\title{
A árdua tarefa de estabelecer padrões de desempenho escolar
}

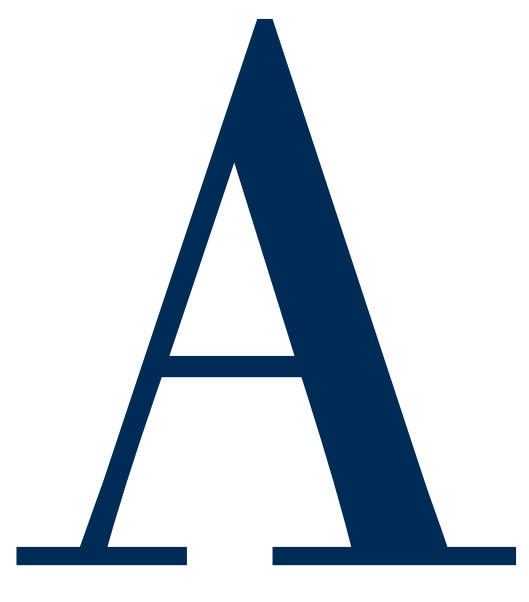

avaliação educacional, em geral, e a avaliação escolar, em particular, vêm se revelando instrumentos fundamentais para se elevar a qualidade do ensino. A experiência internacional, assim como a brasileira, mostra que, para isso, as ações efetivas são as centradas na aprendizagem e na escola. Pesquisas recentes, realizadas por diferentes organismos internacionais - como Unesco - Organização das Nações Unidas para a Educação, a Ciência e a Cultura; OCDE - Organização para a Cooperação e o Desenvolvimento Econômico; e Preal - Programa de Promoção da Reforma Educativa na América Latina e Caribe, entre outros - destacam a importância e as diferentes finalidades das avaliações educacionais para melhorar a qualidade do desempenho dos alunos e das escolas.

A realização de avaliações em larga escala, nacionais e internacionais, como forma de conhecer melhor a dinâmica dos processos e resultados dos sistemas educacionais, é, sem dúvida, uma tendência cada vez mais presente em países de diferentes culturas e orientações ideológicas de governo.

Prova disso é a existência de sistemas nacionais de avaliação em 19 países da América Latina e a sua crescente participação nas avaliações internacionais, como o PISA - Programa Internacional de Avaliação de Alunos e o TIMSS - Third International Mathematics and Science Study, conduzido pelo IEA - International Association for the Evaluation of Educational Achievement, ao

* Maria Helena Guimarães de Castro é professora de Ciência Política da Universidade Estadual de Campinas/Unicamp e pesquisadora associada do Núcleo de Políticas Públicas da Unicamp. Foi presidente do Instituto Nacional de Estudos e Pesquisas Educacionais/INEP, de 1995 a 2001, e secretária-executiva do MEC em 2002. Entre janeiro de 2003 e março de 2006, foi secretária estadual de Desenvolvimento Social do Estado de São Paulo. Foi secretária estadual de Ciência e Tecnologia de São Paulo em 2006. Atualmente é secretária de estado de Educação do Distrito Federal. 
lado de países da União Européia, Ásia, África e América do Norte.

Além disso, observa-se uma tendência mais acentuada para o desenvolvimento de sistemas subnacionais em todo o mundo, assim como no Brasil.

Esta convergência em torno das avaliações "estandardizadas" origina-se de visões, interesses e perspectivas distintas quanto ao papel dos sistemas educativos, como destaca Pedro Ravela (2006), em recente documento do Preal. Em alguns casos, predominam a preocupação com a formação cidadã e a consolidação de uma sociedade democrática; em outros, a produtividade da força de trabalho e a competitividade da economia nacional. Alguns valorizam as avaliações para promover mais oportunidades para o desenvolvimento integral das pessoas e mais possibilidades de participação na sociedade do conhecimento; outros consideram a educação de qualidade uma política estratégica para melhorar a eqüidade e um dos caminhos para superar a pobreza.

Independente das razões que levam à criação de sistemas de avaliação, parece haver consenso quanto ao seu papel como instrumento para se conquistar mais qualidade no ensino. Como os resultados da educação não são diretamente observáveis, nem imediatos, dada a heterogeneidade do corpo docente e da situação socioeconômica familiar dos alunos, só é possível obter uma visão geral do desempenho dos sistemas educacionais mediante uma avaliação externa em larga escala.

\section{Democratização e massificação}

No passado recente, media-se a qualidade de um sistema educativo com base nos indicadores de acesso e permanência na escola, como: matrícula, cobertura, repetência, evasão, anos de estudo etc. 0 ingresso na educação formal era limitado e a maioria dos pobres estava praticamente excluída do sistema ou permanecia poucos anos na escola. A entrada e a permanência no sistema eram consideradas sinônimos de aquisição de conhecimento e das competências básicas.

A progressiva universalização do acesso à escola e a ampliação do número de anos de estudo modificaram essa situação. Os novos alunos, em geral oriundos de famílias pobres e mais vulneráveis, chegam ao sistema educativo em desvantagem em termos de aquisição de bens culturais e de manejo da linguagem oral e escrita. Nesse contexto, a equivalência entre anos de estudo e acesso ao co- nhecimento, ao domínio das competências básicas e capacidades simbólicas nem sempre se concretiza. É verdade que a maior permanência nos sistemas educativos traz alguns benefícios, mas não significa necessariamente que os cidadãos estão aprendendo e incorporando os conhecimentos, as atitudes e as habilidades necessárias para o seu desenvolvimento pessoal e social.

Além disso, a democratização da educação provocou também significativo aumento do número de professores, os quais, infelizmente, não contaram com mecanismos que lhes garantissem sua adequação à nova realidade e a uma boa qualidade de formação. Em geral, o Estado foi omisso na formulação de políticas e no desenvolvimento de mecanismos de controle da qualidade da formação inicial e de programas de aperfeiçoamento docente.

Nesse quadro, o desenvolvimento de sistemas de informação e avaliação transformou-se em peça-chave dos processos de reformas educacionais, que tiveram lugar em diferentes países, especialmente a partir de meados da década de 1980.

Com o objetivo de subsidiar ações para melhorar a qualidade do ensino, as avaliações passaram a dar maior ênfase e divulgação a aspectos centrais do processo de aprendizagem, procurando responder questões, como:

1. O que os alunos estão aprendendo? Em que medida os resultados obtidos correspondem ao que se espera deles ao final dos diferentes ciclos ou níveis de aprendizagem?

2. Qual é o grau de eqüidade observado nos resultados da aprendizagem? Como estão evoluindo os índices de aprendizagem entre os diversos grupos sociais? Como as desigualdades sociais, econômicas e culturais de uma sociedade incidem sobre as oportunidades de aprendizagem?

3. Quais e como os fatores associados afetam, positivamente ou não, os resultados da aprendizagem? Quais os efeitos da repetência ou do processo de alfabetização nas séries iniciais? Ou do tamanho das turmas, tipo de formação dos professores, acesso à educação infantil? Ou da participação dos pais? Como e em que graus tais fatores afetam a aprendizagem?

4. É possível identificar escolas e professores que conseguem fazer com que todos os alunos aprendam, mesmo em contextos sociais desfavorecidos? Quais as características das "boas práticas" que resultam em bom desempenho? 


\section{Um sistema nacional de}

avaliação em larga escala

pode prover informações

indispensáveis para

aprofundar o debate sobre

a situação educacional de

\section{um país.}

5. Quais os efeitos das políticas de educação sobre os resultados da aprendizagem? Em que medida aspectos como salários, carreira e formação dos professores incidem sobre os resultados? Qual o impacto das mudanças curriculares ou mesmo da aquisição de novos materiais didático-pedagógicos sobre a aprendizagem?

Em suma, um sistema nacional de avaliação em larga escala pode prover informações indispensáveis para aprofundar o debate sobre a situação educacional de um país e mostrar o que os alunos estão aprendendo, ou o que deveriam ter aprendido, em relação aos conteúdos e habilidades básicas estabelecidos no currículo. Como os currículos geralmente são muito extensos, a elaboração de provas nacionais obriga a se definirem quais aprendizagens devem ser consideradas fundamentais e asseguradas a todos os alunos, o que se aplica também às avaliações internacionais, que permitem comparações entre países ou regiões.

No Brasil, o desenvolvimento de um sistema de avaliação da educação básica é bastante recente. Até o início dos anos 1990, com exceção do sistema de avaliação da pós-graduação sob a responsabilidade da Capes, as políticas educacionais eram formuladas e implementadas sem qualquer avaliação sistemática. Não era possível saber se elas produziam os resultados desejados.

Em pouco mais de uma década, foi construído um complexo e abrangente sistema de avaliação educacional no país, que cobre todos os níveis da educação. Esse sistema produz informações que orientam as políticas educacionais em todos os níveis de ensino:

1. Sistema de Avaliação da Educação Básica - SAEB Avalia os sistemas públicos e privados de ensino fundamental e médio, com base em amostra de alunos e escolas.

2. Exame Nacional de Ensino Médio - ENEM

De caráter voluntário, avalia as competências e habilidades adquiridas por estudantes que concluíram ou estão concluindo o ensino médio.

\section{Sistema Nacional de Avaliação do Ensino Superior} - Sinaes

Engloba a avaliação de desempenho de cursos e instituições.

4. Prova Brasil

Avalia o universo dos alunos das séries finais dos ciclos I e II do ensino fundamental obrigatório.

Além das avaliações nacionais, o Brasil passou a participar de avaliações internacionais, como o Programa Internacional de Avaliação de Estudantes - PISA, coordenado pela OECD, e o Laboratório de Avaliação da Qualidade da Educação - LECE, coordenado pela Unesco/OREALC - Escritório Regional da Unesco para a América Latina e Caribe, do Chile.

Neste artigo, examino apenas o SAEB e algumas experiências estaduais de avaliação escolar.

\section{O contexto dos anos 1990}

No plano educacional, assim como no plano socioeconômico, as diferenças entre estados e regiões brasileiras são bastante pronunciadas. Em 2004, no estado de São Paulo, $94 \%$ da população com mais de dez anos era alfabetizada, enquanto no estado de Alagoas, apenas $68 \% 0$ era. Metade dos trabalhadores da região Nordeste tinha, no máximo, quatro anos de estudo e apenas $27 \%$ completavam oito anos de estudo ou mais, situação oposta à da região Sudeste, onde mais de $55 \%$ dos trabalhadores estudavam durante oito anos ou mais.

Segundo a Constituição brasileira, Governo Federal, estados e municípios têm responsabilidades distintas e complementares em todos os setores de políticas públicas, inclusive no educacional. A Lei Magna garante, ainda, ampla autonomia aos estados e municípios para estruturarem os seus próprios sistemas de ensino e estimula a descentralização. Assim, a oferta de educação pública, que já era descentralizada e bastante estadualizada, ganhou novo impulso descentralizador com a Constituição de 1988 e com a Lei de Diretrizes e Bases da Educação Nacional, de 1996, que fomenta a criação de sistemas municipais de ensino. Hoje, existe, no Brasil, um número quase tão grande de sistemas de ensino quanto de estados e de municípios!

Nesse sistema altamente descentralizado, em um país marcado por extrema heterogeneidade e desigualdade, foram atribuídas, ao Governo Federal, funções de regulação e de assistência técnica e financeira a estados 
e municípios. A legislação em vigor determina também que cabe ao Governo Federal avaliar a qualidade do ensino em todo o país e em todos os níveis, com o objetivo de definir prioridades e de elevar a qualidade do ensino. É nesse contexto que foi montado o sistema de avaliação do Brasil.

\section{Sistema Nacional de Avaliação}

\section{O Sistema Nacional de Avaliação da Educação Básica}

- SAEB foi criado e aplicado em caráter experimental no início da década de 1990, contando com o apoio financeiro do Banco Mundial. O objetivo do SAEB é avaliar a qualidade da educação oferecida pelos sistemas de ensino existentes, identificando o que os alunos sabem e são capazes de fazer nas diferentes etapas do seu percurso escolar. A partir de 1995, o SAEB foi reformulado do ponto de vista metodológico e passou a ser regularmente realizado a cada dois anos em todo país.

O SAEB consiste de questionários aplicados a uma amostra de professores e diretores de escolas e de provas ministradas a uma amostra de alunos de escolas públicas e privadas que cursam a última série de cada ciclo de estudos do sistema de educação básica.

Assim, participam da amostra:

- alunos da $4^{\underline{a}}$ série do ensino fundamental;

- alunos da 8 $8^{\underline{a}}$ série do ensino fundamental, último ano de educação obrigatória;

- alunos da $3^{\text {a }}$ série do ensino médio, último ano da Educação Básica.

A amostra do SAEB é aleatória, baseada nos resultados do Censo Escolar realizado anualmente e na melhor técnica estatística. Representa os alunos das escolas estaduais, municipais e particulares, urbanas e rurais, de cada um dos 26 estados da Federação e do Distrito Federal. No SAEB, são testados, a cada dois anos, os conhecimentos dos alunos em Matemática e Língua Portuguesa. Eventualmente, são também testados seus conhecimentos de História, Geografia e Ciências.

Para representar este enorme universo de cerca de 44 milhões de alunos em mais de 200 mil escolas, distribuídas entre uma miríade de sistemas de ensino, a amostra do SAEB 2001 envolveu cerca de 280 mil alunos de sete mil escolas, localizadas em mais de dois mil municípios em todo o país. Em 2003, foram 300 mil alunos, 6.300 escolas e 17 mil professores. 
A partir dos resultados dessas provas, os alunos dos diferentes estados e, dentro de cada estado, das diferentes redes de ensino, são classificados em uma escala de desempenho que permite identificar aquilo que eles sabem e são capazes de fazer e aquilo que eles não sabem, mas deveriam saber naquela etapa de seus estudos.

Essas informações são de extrema importância para que os professores e as autoridades educacionais possam tomar medidas para melhorar o desempenho dos alunos em suas escolas.

Além de avaliar o nível alcançado pelos alunos, o SAEB coleta uma série de informações sobre os fatores associados ao desempenho escolar por meio da aplicação de questionários a alunos, professores e diretores de escola. Dessa forma, são obtidas informações socioeconômicas, sobre hábitos de estudo dos alunos, formação e prática dos professores e sobre a gestão das escolas.

O cruzamento dessas informações com os dados de desempenho dos alunos permite detectar quais fatores escolares e extra-escolares exercem uma influência mais forte, positiva ou negativa, sobre o preparo dos alunos.

Por intermédio do SAEB, já foi possível identificar uma série de tendências presentes no diagnóstico da educação no Brasil, as quais passaram a orientar a formulação e reformulação das políticas educacionais.

Por exemplo, o SAEB diagnosticou que, quanto maior é a defasagem série-idade, pior é o desempenho do aluno. No Brasil, o número de alunos em atraso escolar é bastante alto devido às altas taxas de repetência. A repetência, que idealmente serviria como uma nova oportunidade para os alunos de fraco desempenho fortalecerem os seus conhecimentos para, posteriormente, prosseguirem seus estudos, tem-se mostrado mais perversa do que benéfica. Alunos repetentes acabam ficando desestimulados, apresentando desempenho cada vez mais baixo, até abandonarem a escola.

Os resultados do SAEB indicaram que, para melhorar o desempenho geral dos alunos, seria necessário reduzir a defasagem série-idade. Foram criados, então, os programas de aceleração de aprendizagem, voltados para os alunos com mais de dois anos de atraso. Estes programas, aplicados em diversas partes do Brasil, vêm tendo efeitos positivos na correção do fluxo escolar e na redução das taxas de abandono. Espera-se que, nos próximos anos, esses efeitos positivos também se façam sentir no desempenho escolar dos alunos. 
O SAEB também constatou que alunos cujos professores receberam formação de nivel superior têm melhor desempenho na avaliação. Por isso, o Ministério da Educação criou incentivos para os professores obterem uma formação adequada.

Quanto à influência da escola sobre o desempenho dos alunos, o SAEB percebeu que certos estilos de gestão do diretor e a participação dos pais na vida da escola têm efeito positivo. Para elevar o desempenho escolar nas regiões menos favorecidas, foi criado um projeto, com financiamento do Banco Mundial (Fundescola), voltado para o desenvolvimento das escolas.

$\mathrm{Na}$ avaliação desse projeto, utilizaram-se os resultados do SAEB e, mais uma vez, emergiu uma correlação significativa entre o desempenho escolar e a forma de gestão da escola, confirmando a tendência anteriormente identificada. Alunos de escolas que participaram do projeto Fundescola tiveram um desempenho superior nos testes do SAEB em relação aos alunos de outras escolas, com características similares, que dele não participaram.

\section{Avaliações estaduais}

Embora o SAEB não apresente resultados por escola, e sim por sistemas de ensino em cada estado, as informações que ele reúne permitem identificar claramente que tipo de escola favorece um bom desempenho de seus alunos nos testes. Esse fato, por si só, já indica o caminho a ser seguido pelos sistemas de ensino, a fim de elevar a sua qualidade.

No entanto, o SAEB não substitui a avaliação centrada na escola, nem pretende fazê-lo. Ao contrário, no período de 1995 a 2002, o INEP - Instituto Nacional de Estudos e Pesquisas Educacionais Anísio Teixeira, instituição responsável pelo SAEB, estabeleceu uma linha de apoio e assistência técnica aos estados e municípios para que desenvolvessem os seus próprios sistemas de avaliação. O SAEB oferece um diagnóstico consistente da situação educacional em todo país, permitindo comparações entre os diferentes sistemas de ensino. No entanto, cabe a cada um deles desenvolver os seus próprios sistemas de avaliação para retratar a realidade de cada escola, sob sua direta responsabilidade, e definir ações de melhoria e monitoramento sistemáticos.

Nesse sentido, o Governo Federal passou a oferecer, aos estados e municípios interessados em desenvolver os

\author{
Cabe a cada sistema \\ educacional desenvolver \\ seus métodos de avaliação \\ para retratar a realidade \\ de cada escola, sob sua \\ direta responsabilidade, $e$ \\ definir ações de melhoria \\ e monitoramento \\ sistemáticos.
}

seus próprios sistemas de avaliação, treinamento para as equipes elaborarem os seus próprios testes. Além disso, disponibiliza alguns itens-âncora para integrar as provas, assegurando assim a comparabilidade dos resultados regionais com os nacionais.

O desenvolvimento de sistemas regionais ou locais de avaliação, em articulação com o sistema nacional, apresenta uma série de vantagens. Primeiro, eles proporcionam uma investigação mais aprofundada sobre as especificidades regionais ou locais, o que não é possível no SAEB. Segundo, eles permitem a obtenção dos resultados por escola, o que não é viável em um sistema nacional de avaliação como o brasileiro, devido à complexidade envolvida na sua operacionalização e os seus elevados custos. Terceiro, eles possibilitam a coleta de informações de interesse do gestor da rede, o que tampouco é possível em uma avaliação nacional.

Atualmente, cerca de 13 estados brasileiros e duas capitais já possuem sistemas próprios para avaliar as suas redes de ensino, produzindo resultados por escola. Há algumas iniciativas recentes, como a implantação de uma avaliação escolar reunindo um conjunto de municípios gaúchos, situados na região de Caxias do Sul, os quais criaram um consórcio e pactuaram os critérios de avaliação de todas as suas escolas.

No final de 2005, o MEC aplicou, pela primeira vez, a Prova Brasil em 44 mil escolas. Foram testados 5,4 miIhões de alunos de $4^{\underline{a}}$ e $8^{\underline{a}}$ séries das escolas públicas em Língua Portuguesa e Matemática. Os resultados permitiram comparar os resultados das escolas com a escala de proficiência do SAEB.

O principal aspecto positivo da Prova Brasil é possibilitar a comparação entre as escolas da mesma rede de ensino e, com isso, prover informações para apoiar diretores e professores nos projetos pedagógicos. Infelizmente, 
as escolas e sistemas de ensino têm tido dificuldade em usar os resultados e compreender a metodologia adotada. Falta uma política séria e consistente de divulgação e uso dos resultados das avaliações. O Brasil avançou muito na montagem e desenvolvimento de sistemas nacionais e estaduais, mas o grande problema é a dificuldade das escolas e dos professores em usar os resultados para melhorar suas aulas.

A título de exemplo, apresentarei um breve panorama de dois sistemas estaduais de avaliação dos dois maiores estados do Brasil: São Paulo e Minas Gerais.

\section{São Paulo e Minas Gerais}

Em 2005, havia, no estado de São Paulo, aproximadamente, oito milhões de alunos matriculados no ensino fundamental e médio, $87 \%$ dos quais em cerca de 12.500 escolas públicas estaduais e municipais. No mesmo ano, no estado de Minas Gerais, havia cerca de quatro miIhões e 400 mil alunos matriculados nos mesmos níveis de ensino, $93 \%$ deles em mais de 14.500 escolas públicas. Para monitorar a qualidade do ensino ofertado por suas escolas, que concentram quase um terço dos alunos do país, os governos desses dois estados decidiram estabelecer seus próprios sistemas de avaliação.

O estado de São Paulo criou, em 1996, o Sistema de Avaliação do Rendimento Escolar do Estado de São Paulo Saresp, e Minas Gerais, o Programa de Avaliação da Rede Pública de Educação Básica - Proeb.

Esses sistemas estaduais de avaliação são abertos à participação dos municípios daqueles estados que tiverem rede de escolas municipais e que a eles desejarem aderir.

Como o SAEB, esses dois sistemas avaliam periodicamente os conhecimentos de seus alunos em Português, Matemática, Ciências, História e Geografia e, por meio de questionários, recolhem outras informações associadas ao desempenho.

\section{O Proeb de Minas Gerais}

O Proeb aplica testes a todos os alunos de $4^{\underline{a}}, 8^{\underline{a}}$ e $11^{\underline{a}}$ série da rede estadual. 0 ciclo de avaliação do Proeb se completa a cada dois anos. Por exemplo, em 2000, foram aplicados testes de Português e de Matemática, e, em 2001, de História, Geografia e Ciências. Integram a avaliação, questionários destinados aos alunos, professores e diretores de escola, com o objetivo de se levantar dados sobre o processo de gestão das escolas, o perfil dos profissionais da Educação e dos estudantes atendidos, e os recursos e serviços disponíveis nas escolas.

Os resultados dos testes e dos questionários fornecem um conjunto de dados que possibilita um diagnóstico detalhado da situação educacional no estado. Diferentemente do SAEB - que analisa comparativamente o desempenho dos alunos entre os diferentes estados e sistemas de ensino sem atentar para as políticas educacionais específicas -, o Proeb avalia o desempenho dos alunos à luz das políticas educacionais implementadas no Estado. Ainda que orientado para subsidiar a formulação e a redefinição das políticas educacionais do governo do estado, o sistema de avaliação de Minas Gerais utiliza a mesma escala de proficiência do SAEB, a fim de garantir a comparabilidade dos seus resultados com os resultados nacionais.

O Proeb faz parte do Sistema Mineiro de Avaliação da Educação Pública - Simave, rede que abrange 27 instituições de ensino superior, públicas e privadas, 41 superintendências regionais de ensino, representantes dos municípios, dos alunos e dos professores. Ao integrar os diferentes segmentos da sociedade envolvidos com a educação no sistema de avaliação, o Simave procura desenvolver uma nova cultura de avaliação que leve à ruptura das práticas tradicionais e ineficientes ainda em vigor no cotidiano de muitas escolas.

A participação direta das instituições de ensino superior no processo de avaliação é crucial, uma vez que são elas as responsáveis pela formação dos professores para as escolas da região. Por meio do trabalho conjunto, procura-se aproximar as instituições de ensino superior do trabalho pedagógico da escola em todas as suas dimensões. Esta associação favorece e estimula a discussão de possíveis mudanças nos cursos de formação de professores, para torná-los mais sensíveis às necessidades do ensino público. A distância entre a universidade e seus cursos de formação de professores e as reais necessidades da escola pública tem-se revelado um dos grandes entraves para a elevação da qualidade da educação no país.

A avaliação das escolas pelo Proeb está pautada pelos princípios da eqüidade e publicidade. Ao identificar os problemas de uma escola e apontar os caminhos para saná-los, age-se no sentido de proporcionar uma educação de qualidade para todas as crianças, e, ao se divulgarem os resultados da avaliação, informa-se, 
Para além dos fatores socioculturais que incidem diretamente no desempenho dos alunos, sobre os quais a influência do sistema educacional é muito pequena, existe uma grande margem de ação que é propriamente educativa e que se desenvolve em sala de aula. A participação do professor em todas as etapas da avaliação, proporcionada por algumas experiências estaduais, como o Saresp, parece ser uma boa estratégia de levar, para a sala de aula e para a prática docente, os conhecimentos trazidos pela avaliação.

0 trabalho conjunto entre as instituições de ensino superior e as autoridades regionais de educação de $\mathrm{Mi}$ nas Gerais, propiciado pelo Proeb, também é aparentemente um caminho bastante sugestivo para encurtar a distância que separa a formação dos professores das necessidades reais das escolas, as teorias de ensino e aprendizagem das práticas docentes.

Para que os resultados tenham impacto sobre as

0 desenvolvimento e 0 aperfeiçoamento dos instrumentos de avaliação são um trabalho contínuo e dele depende os futuros progressos na educação. Se os instrumentos para a avaliação de conteúdos já são razoavelmente desenvolvidos, ainda há muitas dificuldades para se elaborarem instrumentos capazes de medir a aquisição e o desenvolvimento de competências e habilidades cognitivas. Além do domínio propriamente cognitivo, seria importante investigar o desenvolvimento de outras habilidades e competências necessárias ao indivíduo na sociedade contemporânea, mas, disso, estamos ainda mais longe.

No plano nacional, segue sendo um grande desafio estabelecer padrões (standards) de desempenho escolar passíveis de comparação num quadro de grande diversidade regional, como o brasileiro.

Também nas avaliações estaduais ou municipais, muito ainda resta a ser aperfeiçoado para se medir o valor agregado pela escola ao aluno, tendo em vista a variada bagagem cultural que cada um traz ao entrar na escola, variação acentuada pelas enormes desigualdades socioeconômicas que marcam o país.

Enfim, ainda nos falta maior precisão na identificação e ponderação dos fatores internos e externos à escola que incidem no desempenho dos alunos.

No entanto, o grande desafio continua sendo a utilização, em sala de aula, dos resultados obtidos por meio dos instrumentos já existentes para o aperfeiçoamento da prática docente e para a elevação da qualidade do ensino. políticas educativas, é preciso investir pesadamente na análise, compreensão e discussão dos resultados, envolvendo, no processo, todos os atores relevantes, autoridades educativas, professores, pais de alunos e dirigentes. É imprescindivel devolver os resultados das avaliações censitárias ou universais para as escolas, professores e pais de alunos. É fundamental que todos estabeleçam um acordo para enfrentar as deficiências identificadas e definir ações e estratégias para superá-las.

Além da disposição em dar transparência aos resultados, os gestores devem investir muito na comunicação apropriada e permanente dos resultados para a opinião pública.

Apesar de todas as dificuldades e dos obstáculos a serem superados, é certo que a avaliação é um bom caminho para a melhoria da qualidade do ensino. No caso brasileiro, o sistema de avaliação deve compatibilizar o imperativo da eqüidade, sem a qual não existe uma nação propriamente dita, com a diversidade constitutiva de suas dimensões continentais e formação histórica.

A integração flexível entre um sistema nacional de avaliação - como o SAEB e a Prova Brasil - e os sistemas locais ou regionais de avaliação - como o Saresp e o Proeb - parece ser o modelo mais condizente com a estrutura político-administrativa de nossa Federação e com as necessidades da educação brasileira. 